\title{
Long-term effects of tongue piercing - a case control study
}

\author{
Dirk Ziebolz • Aick Hildebrand • Peter Proff • \\ Sven Rinke • Else Hornecker • Rainer F. Mausberg
}

Received: 1 March 2010 / Accepted: 9 January 2011 / Published online: 27 January 2011

(C) The Author(s) 2011 This article is published with open access at Springerlink.com

\begin{abstract}
The aim of this study was to evaluate tooth and periodontal damage in subjects wearing a tongue piercing (TP) in comparison to matched control subjects without tongue piercing. Members of the German Federal Armed Forces who had TP (group TP) and a matched control group (group C) volunteered to take part in the study. The time in situ, localization and material of TP were documented. Dental examinations included DMF-T, oral hygiene, enamel fissures (EF), enamel cracks (EC) and recessions. Statistical analysis was determined by $\chi^{2}$ test and the $t$ test. Both groups had 46 male subjects (mean age 22.1 years). The piercings had been in situ for $3.8 \pm$ 3.1 years. Subjects in the TP group had a total of 1,260 teeth. Twenty-nine subjects had 115 teeth $(9.1 \%)$ with EF (67\% lingual). In group C (1,243 teeth), 30 subjects had 60 teeth with $\mathrm{EF}(4.8 \%, 78 \%$ vestibular $)(p<0.01)$. Thirty-
\end{abstract}

D. Ziebolz $(\bowtie) \cdot$ E. Hornecker $\cdot$ R. F. Mausberg

Department of Preventive Dentistry,

Periodontology and Cariology,

University Medical Centre Goettingen,

Robert-Koch-Str. 40,

37075 Goettingen, Germany

e-mail: dirk.ziebolz@med.uni-goettingen.de

\section{A. Hildebrand}

German Army Dental Office,

Dickenrücker Strasse 16,

36199 Rotenburg a.d. Fulda, Germany

P. Proff

Department of Orthodontics, University of Regensburg,

Franz-Josef-Strauss-Allee 11,

93053 Regensburg, Germany

S. Rinke

Private Practice,

Geleitstr. 68,

63456 Hanau, Germany eight subjects belonging to group TP had EC in 186 teeth $(15 \%)$. In group C, 26 subjects with 56 teeth $(4.5 \%)$ were affected by EC $(p<0.001)$. Twenty-seven subjects in group TP had 97 teeth $(7.7 \%)$ with recessions. Lingual surfaces of anterior teeth in the lower jaw were affected most frequently (74\%). In group C, 8 subjects had 19 teeth $(1.5 \%)$ with recessions (65\% vestibular). Differences between the two groups were statistically significant $(p<0.001)$. Tongue piercing is correlated with an increased occurrence of enamel fissures, enamel cracks and lingual recessions. Patients need better information on the potential complications associated with tongue piercing.

Keywords Tongue piercing · Enamel fissures · Enamel cracks $\cdot$ Lingual recessions $\cdot$ Case control study

\section{Introduction}

Body art leaving a permanent impression such as tattooing and piercing, has been practiced for many centuries by diverse ethnic groups for religious, ritualistic and other reasons $[1,2]$. In Western societies, piercing has become more and more popular although, just a few years ago, it was considered to be the expression of a rather eccentric lifestyle [2-4]. Today, body piercing enjoys widespread popularity, especially among the young people of Europe and North America where it is practised for body adornment [2].

Piercing is the perforation of the skin and underlying tissue, usually for permanently inserting jewellery. The most common piercing sites are the navel, the nipples and particularly, the face. Although the earlobe continues to be the most popular site for piercing, the orofacial areaincluding lips, labiomental groove, cheeks, nose, eyebrows 
and above, all the tongue - is becoming increasingly popular. Other intraoral piercing sites include the upper frenulum and even the uvula [5]. Dental practitioners are coming into contact with a growing number of patients with oral piercings, especially tongue piercings (TP) [5-7]. In the majority of cases, piercing of the tongue is performed at the midline [8]. Barbell-shaped devices are among the most widely used items of jewellery. Piercing objects are made of different materials, most commonly metals such as stainless steel or titanium $[1,5]$. Recently, synthetic materials like Teflon and nylon or plastic have also been used.

Due to the increasing popularity of tongue piercing, dental professionals are being confronted with numerous oral and dental complications or risks associated with this practice [9]. From a medical perspective, the use of body jewellery cannot be considered to be a harmless fashion trend, since it can produce undesired local and general effects. Peticolas et al. have made a distinction between two different types of complications during piercing; those immediately following piercing and long-term complications [5]. Moreover, wearing tongue jewellery over a long period of time may result in the colonisation of periodontopathogenic bacteria at the piercing site, especially if the subject does not carry out appropriate oral hygiene practices [10].

Literature related to the medical aspects is limited and mainly relates to case reports, a few studies with only a limited number of patients and two review articles $[9,10]$. Based on these, the most commonly described oral consequences are damage to the teeth and periodontal alterations caused by tongue piercing [1, 3, 6, 7, 9-19]. However, up until now, no case control or longitudinal studies have been available in which a clear correlation between tongue piercing and longterm oral damage has been established.

The aim of this study was to evaluate tooth and periodontal damage in subjects wearing a tongue piercing in comparison to matched control subjects without tongue piercing. The hypothesis of the study was: wearing a tongue piercing promotes more tooth and periodontal damage than not wearing a tongue piercing.

\section{Materials and methods}

\section{Population}

Subjects were selected during routine dental examinations at a training unit of the German Federal Armed Forces (Rotenburg a.d. Fulda, Germany). A total of 1,884 subjects (aged 18 to 27 years) were examined over an observation period of 12 months. Those with a tongue piercing were asked to volunteer to participate in the study. Fifty-five subjects $(m=50, w=5)$ wore one or more tongue piercings (prevalence of $2.9 \%$ ) and four declined to participate in the study. The five female subjects were not included because of a too limited number of cases. The tongue piercing group (group TP) therefore consisted of 46 subjects (mean age 22.2 years, range 19 to 26 years). In accordance with the requirement profile of a matched-pair design, each TP subject was paired with a randomly selected male subject who had no tongue piercing. The age difference between each member of the pair was not allowed to exceed \pm 1 year. All subjects in the control group (group C) were volunteers. The mean age of group $\mathrm{C}$ was 22.1 years (range 18 to 27 years). The study was registered and approved by the Ethics Committee of the Federal Ministry of Defence (application no. 3/01/05).

\section{Questionnaire}

Before participating in the study, all subjects were requested to fill out a questionnaire with questions about age, education, smoking habits, alcohol and drug consumption and oral hygiene habits. Furthermore, former orthodontic treatment and dental trauma were asked. Group TP filled out an additional questionnaire concerning the length of time the piercing(s) had been worn, the shape of the piercing(s) and the material from which it or they were made and who applied the TP (piercing artist, dentist or physician) and the length of time between each cleaning of the object (applied as a piercing).

\section{Clinical examination}

All subjects were examined under standardized conditions by a calibrated dentist (kappa value $>0.8$ ). The dental examination of both groups first documented decayed, missing, filled teeth (DMF-T), the degree of gingival inflammation and oral hygiene. Then, all subjects received a prophylaxis prior to examining the teeth for enamel defects (e.g. enamel fissures $=\mathrm{EF}$; enamel cracks $=\mathrm{EC}$ and grooveshaped abrasions $=\mathrm{GA}$ ) as well as periodontal changes, e.g. vestibular and oral recessions (R). In addition, the length of the piercing post was evaluated with an orthodontic caliper and a ruler, and the piercing site was documented.

$D M F-T$ : Data were acquired using a mirror and a probe. All teeth with a dentine cavity or a reasonable suspicion of dentine caries were assigned to category D. Filled and crowned teeth were assigned to $\mathrm{F}$.

Gingival inflammation and oral hygiene: Gingival inflammation was determined with the modified sulcus bleeding index (SBI). Oral hygiene was evaluated with the QuigleyHein index (QHI, plane surfaces) and the approximal space plaque index (API) after staining (MIRA-2-TON, Hager \& Werken GmbH, Duisburg/Germany). 
Enamel damage: Enamel damage was clinically evaluated with a mirror, a probe and an ultraviolet (UV) lamp under standardized conditions of illumination. Enamel fissures were documented with reference to the respective surfaces. The coronal enamel of all teeth was illuminated with a UV light polymerization lamp. Finally, every tooth was blowdried thoroughly and examined for enamel cracks. The incisor ridge respectively the chewing surfaces of the teeth were checked for groove-shaped abrasions.

Periodontal changes: Gingival recessions were documented with reference to the tooth surface affected. Therefore, the vestibular and oral recessions were measured from the cementum-enamel junction to the gingival margin with a millimeter-scaled periodontal probe (CP-15UNC, Hu-Friedy, Chicago, IL, USA).

\section{Statistical analysis}

Statistical analysis was performed with the commercially available program SPSS 14.0 (SPSS, Inc., Chicago, IL, USA). Data were statistically evaluated using the chi-squared test followed by a $t$ test. Level of significance was set at $\alpha=0.05$.

\section{Results}

\section{Questionnaire}

The distribution of education, smoking and oral hygiene habits, alcohol and drug consumption as well as former orthodontic treatment and dental trauma was similar in both study groups (Table 1). The majority of the participants in both groups had visited the middle school (TP: 46\%, C:
$37 \%$ ) and the elementary school (TP: $50 \%$, C: $52 \%$ ), were smokers (TP: $89 \%$, C: 76\%), drink alcoholic beverages occasionally (TP: $87 \%, \mathrm{C}: 76 \%$ ) and brush their teeth twice a day (TP: $87 \%$, C: 76\%) (Table 1).

Information about the piercing: The mean period in situ was 3.8 years (range from 6 months to 9 years). As two subjects each wore two tongue piercings, a total of 48 dumbbell-shaped piercing objects was documented. Fortyfive piercing objects were located at the anterior third of the tongue and three in the middle to rear of the tongue. The shape and material of the upper dumbbell and the material of the piercing posts differed. Ball-shaped closures were most frequently found $(94 \%)$, followed by cone-shaped $(4 \%)$ and cylindrical $(2 \%)$ closures. These were made of titanium $(65 \%)$, steel $(25 \%)$, acrylic $(6.3 \%)$ and niobium $(5 \%)$. Reasons for wearing a tongue piercing includes fashion trend $(46 \%)$, nice jewellery (22\%) and sex (13\%); $7 \%$ stated the TP was a gift and $12 \%$ did not answer this question.

The length of the piercing posts was 20 to $35 \mathrm{~mm}$ (mean $26 \mathrm{~mm})$. Forty subjects $(86.9 \%)$ had their piercing inserted in a piercing studio, and six (13\%) in a practice or clinic applied by a physician or dentist. Prior to piercing, 43 subjects $(93.5 \%)$ were advised of possible tooth damage due to piercing objects. Thirty-eight subjects $(82.6 \%)$ declared to remove their piercing object at regular intervals for cleaning and eight subjects (17.4\%) wore the piercing object permanently without cleaning.

\section{Clinical examination}

DMF-T and oral hygiene: Subjects in group TP had a total of 1,260 teeth (group C: 1,243 teeth). With regard to group DMF-T, no difference between group TP $(9.8 \pm 4.3)$ and
Table 1 School education, smoking habits, alcohol and drug consumption, former orthodontic treatment and dental trauma as well as oral hygiene habits of the participants (group TP: $n=46$; group C: $n=46$ )

TP tongue piercing, $C$ control group

\begin{tabular}{llrr}
\hline & & TP group $(n=46)$ & C group $(n=46)$ \\
\hline School education & Secondary school & $2(4 \%)$ & $5(11 \%)$ \\
& Middle school & $21(46 \%)$ & $17(37 \%)$ \\
& Elementary school & $23(50 \%)$ & $24(52 \%)$ \\
Smoker & & $41(89 \%)$ & $35(76 \%)$ \\
Alcohol consumption & No & $5(11 \%)$ & $7(15 \%)$ \\
& Occasionally & $40(87 \%)$ & $35(76 \%)$ \\
Drugs consumption & Daily & $1(2 \%)$ & $4(9 \%)$ \\
Former orthodontic treatmen) & & & \\
Dental trauma & Accidental & $18(39 \%)$ & $17(37 \%)$ \\
\multirow{2}{*}{ Oral hygiene: brushing } & Conditional upon wearing a TP & $7(15 \%)$ & \\
& 1x/day & $5(11 \%)$ & $3(17 \%)$ \\
& 2x/day & $40(87 \%)$ & $35(76 \%)$ \\
Oral hygiene: flossing & 3x/day & $1(2 \%)$ & $3(7 \%)$ \\
\hline
\end{tabular}


Table 2 Mean value $(m) \pm$ standard deviation (SD) of DMF-T, D-T, M-T, F-T, API, QHI (oral hygiene) and SBI (gingival inflammation) in the two groups

\begin{tabular}{|c|c|c|c|c|c|c|c|}
\hline & DMF-T $m \pm$ SD & $\mathrm{D}-\mathrm{T} m \pm \mathrm{SD}$ & $\mathrm{M}-\mathrm{T} m \pm \mathrm{SD}$ & $\mathrm{F}-\mathrm{T} m \pm \mathrm{SD}$ & API $m \pm$ SD & SBI $m \pm$ SD & $\mathrm{QHI} m \pm \mathrm{SD}$ \\
\hline TP group $(n=46)$ & $9.8 \pm 4.3$ & $2.0 \pm 2.1$ & $0.6 \pm 1.1$ & $7.2 \pm 3.5$ & $68.2 \pm 27.2 \%$ & $62.2 \pm 29.3 \%$ & $2.1 \pm 1.3$ \\
\hline C group $(n=46)$ & $8.8 \pm 4.4$ & $0.5 \pm 1.1$ & $1.0 \pm 1.7$ & $7.3 \pm 3.8$ & $23.8 \pm 17.9 \%$ & $18.9 \pm 16.6 \%$ & $2.2 \pm 0.9$ \\
\hline$p$ value & $<0.269$ & $<0.001$ & $<0.226$ & $<0.549$ & $<0.001$ & $<0.001$ & $<0.669$ \\
\hline
\end{tabular}

$D M F-T$ decayed, missing, filled teeth, $D-T$ decayed teeth, $M-T$ missing teeth, $F-T$ filled teeth, $A P I$ approximal space plaque index, $S B I$ sulcus bleeding index, $Q H I$ Quigley-Hein index, $T P$ tongue piercing, $C$ control, $m \pm \mathrm{SD}$ : mean+standard deviation

group C (8.8 \pm 4.4$)(p=0.296)$ was established. This also applied to M-T $(p=0.226)$ and F-T $(p=0.549)$ (Table 2). Both groups varied only in the D-T component; group TP showed significantly more carious teeth $(p<0.001)$. While no difference between group $\mathrm{TP}$ and $\mathrm{C}$ was determined in relation to the cleaning of the plane surfaces (QHI), group TP revealed significantly more serious conditions for API and SBI than group C $(p<0.001)$ (Table 2).

Enamel fissures: In group TP, 29 subjects had 115 teeth with EF (9.1\%), $33 \%$ affected the vestibular and $67 \%$ the oral/lingual tooth surfaces. In group C, 30 subjects had 60 teeth with EF (4.8\%) (78\% vestibular, $22 \%$ oral/lingual). Differences between both groups were significant $(p<0.01)$ (Table 3 ). Tables 4 and 5 show the distribution pattern of teeth with oral EF.

Enamel cracks: Thirty-eight subjects belonging to group TP had 185 teeth with EC (15\%). In group C, 26 subjects were diagnosed with EC in a total of 56 teeth $(4.5 \%)$. Differences between both groups were significant $(p<0.001)$ (Table 3). Tables 4 and 5 show the distribution pattern of teeth with EC.

Groove-shaped abrasions: In group TP, occlusal/incisal GA $(2.6 \%)$ were determined in 18 subjects on a total of 33 teeth (anterior and posterior). In group C, 6 subjects showed these findings on 19 teeth (anterior only, 1.5\%).
With regard to GA, no significant difference between the two groups was established $(p=0.26)$ (Table 3).

Recessions: Group TP included a total of 1,260 teeth, 27 subjects had 97 teeth with recessions (7.7\%). Twenty-six percent of the vestibular and $74 \%$ of the lingual tooth surfaces were affected. Lingual surfaces of mandibular anterior teeth were most frequently affected $(32=12 \%, 31=19 \%, 41=18 \%$, $42=14 \%)$. In group C (1,243 teeth), 8 subjects had 19 teeth with recessions $(1.5 \%)$ (vestibular: $65 \%$, lingual: $35 \%$; $32=5 \%, 31=11 \%, 41=5 \%, 42=0 \%)$. The differences between TP and C were significant $(p<0.001)$ (Table 3).

\section{Discussion}

The present investigation is the first study which compares the teeth of subjects wearing TP with those of a control group without TP in relation to long-term damage. One thousand eight hundred eighty-four subjects (aged 18 to 27 years) were examined. The mean age of the two groups was 22.1 years. In the present study indicating a prevalence of $2.9 \%$, only male participants (German soldiers) were included in the clinical examination. The results show that wearing tongue piercings is correlated with an increased occurrence of enamel fissures, enamel cracks and lingual recessions. However, there was a higher number of EF, EC and $\mathrm{R}$ in the tongue piercing group in comparison to the

Table 3 Mean value $(m) \pm$ standard deviation (SD) of enamel fissures, enamel cracks, groove-shaped abrasions, and recessions in the two groups, as well as the number of subjects affected (\%) and the number of teeth affected (\%) in both groups (group TP: $n=1,260$ teeth; group C: $n=1,243$ teeth)

\begin{tabular}{|c|c|c|c|c|c|c|c|c|c|c|c|c|}
\hline & \multicolumn{3}{|c|}{ Enamel fissures } & \multicolumn{3}{|c|}{ Enamel cracks } & \multicolumn{3}{|c|}{ Groove-shaped abrasions } & \multicolumn{3}{|c|}{ Recessions } \\
\hline & $m \pm \mathrm{SD}$ & $n$ (persons) & $n$ (teeth) & $m \pm \mathrm{SD}$ & $n$ (persons) & $n$ (teeth) & $\begin{array}{l}m \pm \\
\mathrm{SD}\end{array}$ & $n$ (persons) & $n$ (teeth) & $m \pm \mathrm{SD}$ & $n$ (persons) & $n$ (teeth) \\
\hline $\begin{array}{c}\text { TP group } \\
(n=46)\end{array}$ & $\begin{array}{r}2.5 \pm \\
2.8\end{array}$ & $29(63 \%)$ & $115(9.1 \%)$ & $\begin{array}{r}4.0 \pm \\
3.5\end{array}$ & $38(82.2 \%)$ & $185(15 \%)$ & $\begin{array}{r}0.7 \pm \\
1.2\end{array}$ & $18(39.1 \%)$ & $33(2.6 \%)$ & $\begin{array}{l}2.1 \pm \\
2.4 \%\end{array}$ & $27(58.7)$ & $97(7.7 \%)$ \\
\hline $\begin{array}{l}\text { C group } \\
(n=46)\end{array}$ & $\begin{array}{c}1.3 \pm \\
1.3 \\
<0.01\end{array}$ & $30(65.2 \%)$ & $60(4.8 \%)$ & $\begin{array}{c}1.2 \pm \\
1.3 \\
<0.001\end{array}$ & $26(56.5 \%)$ & $56(4.5 \%)$ & $\begin{array}{l}0.4 \pm \\
1.2 \\
<0260\end{array}$ & $6(13 \%)$ & $19(1.5 \%)$ & $\begin{array}{l}0.4 \pm \\
1.1 \% \\
<0.001\end{array}$ & $8(17.4 \%)$ & $19(1.5 \%)$ \\
\hline
\end{tabular}

TP tongue piercing, $C$ control, $m \pm \mathrm{SD}$ : mean+standard deviation 
Table 4 Distribution pattern of oral enamel fissures and enamel cracks (in percentage) according to tooth number of maxillary teeth (FDI numbering system)

\begin{tabular}{lllllllllllllllll}
\hline Maxillary teeth & & $\begin{array}{l}\text { All } \\
(\%)\end{array}$ & $\begin{array}{l}17 \\
(\%)\end{array}$ & $\begin{array}{l}16 \\
(\%)\end{array}$ & $\begin{array}{l}15 \\
(\%)\end{array}$ & $\begin{array}{l}14 \\
(\%)\end{array}$ & $\begin{array}{l}13 \\
(\%)\end{array}$ & $\begin{array}{l}12 \\
(\%)\end{array}$ & $\begin{array}{l}11 \\
(\%)\end{array}$ & $\begin{array}{l}21 \\
(\%)\end{array}$ & $\begin{array}{l}22 \\
(\%)\end{array}$ & $\begin{array}{l}23 \\
(\%)\end{array}$ & $\begin{array}{l}24 \\
(\%)\end{array}$ & $\begin{array}{l}25 \\
(\%)\end{array}$ & $\begin{array}{l}26 \\
(\%)\end{array}$ & $\begin{array}{l}27 \\
(\%)\end{array}$ \\
\hline $\begin{array}{l}\text { Enamel fissures at } \\
\text { oral sites }\end{array}$ & $\mathrm{TP}(n=115)$ & 41 & 1 & 1 & 1 & 1 & 2 & 3 & 10 & 11 & 3 & 3 & 2 & 1 & 1 & 1 \\
Enamel cracks & $\mathrm{C}(n=60)$ & 12 & 0 & 0 & 0 & 0 & 2 & 2 & 3 & 3 & 2 & 0 & 0 & 0 & 0 & 0 \\
& $\mathrm{TP}(n=185)$ & 61 & 2 & 3 & 2 & 1 & 2 & 5 & 15 & 14 & 7 & 1 & 2 & 3 & 2 & 2 \\
& $\mathrm{C}(n=56)$ & 67 & 0 & 0 & 2 & 4 & 0 & 13 & 13 & 20 & 15 & 0 & 0 & 0 & 0 & 0 \\
\hline
\end{tabular}

$T P$ tongue piercing group, $C$ control group

controls. Differences between the two groups were statistically significant $(p<0.001)$.

Tongue piercings are currently in trend worldwide. Wearing a TP appears to be particularly popular in individuals aged between 16 and 24 years [6, 20]. The age of the participants in the present study shows a similar age distribution. However, information about the prevalence of TP is by no means unambiguous. A representative survey of 10,000 subjects $(\mathrm{m} / \mathrm{f})$ in England revealed a prevalence of $1.5 \%$ for tongue piercings, $6.5 \%$ of the subjects aged 16 to 24 years had a TP (in those above 25 years of age it was $0.6 \%$ ) [20]. Other cross-sectional studies have indicated a higher prevalence of TP (varying between $3.4 \%$ and $15.3 \%$, depending on the sample) as the results in the present study [17, 21, 22].

Although Bui et al. described an association of piercings and alcohol, nicotine and drug risk behaviour; [23] this point could not be established in this study. All the participants were soldiers and therefore medically and physically screened prior to the start of their military career. Furthermore, the distribution of alcohol and drug consumption as well as oral hygiene was similar in both study groups. Nevertheless, the oral hygiene situation in the TP group was significantly worse than in the $\mathrm{C}$ group. It is also a matter of concern to read in the available literature that most subjects who wear a tongue piercing do not remove it for cleaning [13]. However, this finding was not to reveal in the present study. The majority of subjects stated that they remove the piercing object for cleaning regularly.
However, from the dental perspective, the popular fashion of TP is a cause for concern when the number of oral complications and risks are considered. In 1994, Scully and Chen were the first to describe complications directly correlated with tongue piercing [6]. Since then, a wide variety of case reports describing the oral complications of TP have been published [1, 3, 8, 9, 13, 24-37]. In addition, the literature is based on a limited number of studies with only a few patients studied and a few reviews [9, 10, 14-19]. A systematic classification of the side effects of tongue piercing documented in the literature suggests that three types of complications can be distinguished: complications during piercing (complications during the initial procedure), complications immediately following piercing (primary postoperative complications) and long-term complications (secondary postoperative complications) [5].

Long-term local complications cover all negative consequences developing after a prolonged in situ presence of the piercing object. The most commonly described oral complication is damage to the teeth and periodontium [1, 6]. Local effects include enamel cracks and tooth fractures resulting from knocking the (usually) ball-shaped tips of the jewellery against the teeth [1]. Many authors have presented clinical cases of fractures involving enamel and dentine $[1,3,12,16,17,24,27,32,33,35-38]$. The available data have established an indisputable causal relationship between tooth fractures and lingual piercing $[15,17,24]$. In general, a diversity of enamel defects like chippings, fissures, complete tooth fractures with or without

Table 5 Distribution pattern of oral enamel fissures and enamel cracks (in percentage) according to tooth number of mandibular teeth (FDI numbering system)

\begin{tabular}{lllllllllllllllll}
\hline Mandibular teeth & & $\begin{array}{l}\text { All } \\
(\%)\end{array}$ & $\begin{array}{l}47 \\
(\%)\end{array}$ & $\begin{array}{l}46 \\
(\%)\end{array}$ & $\begin{array}{l}45 \\
(\%)\end{array}$ & $\begin{array}{l}44 \\
(\%)\end{array}$ & $\begin{array}{l}43 \\
(\%)\end{array}$ & $\begin{array}{l}42 \\
(\%)\end{array}$ & $\begin{array}{l}41 \\
(\%)\end{array}$ & $\begin{array}{l}31 \\
(\%)\end{array}$ & $\begin{array}{l}32 \\
(\%)\end{array}$ & $\begin{array}{l}33 \\
(\%)\end{array}$ & $\begin{array}{l}34 \\
(\%)\end{array}$ & $\begin{array}{l}35 \\
(\%)\end{array}$ & $\begin{array}{l}36 \\
(\%)\end{array}$ & $\begin{array}{l}37 \\
(\%)\end{array}$ \\
\hline $\begin{array}{l}\text { Enamel fissures at oral } \\
\text { sites }\end{array}$ & $\mathrm{TP}$ & 26 & 0 & 0 & 0 & 1 & 1 & 2 & 7 & 9 & 3 & 1 & 2 & 0 & 0 & 0 \\
Enamel cracks & $\mathrm{C}$ & 10 & 0 & 0 & 0 & 0 & 0 & 2 & 3 & 3 & 2 & 0 & 0 & 0 & 0 & 0 \\
& $\mathrm{TP}$ & 39 & 1 & 2 & 2 & 3 & 1 & 5 & 6 & 5 & 3 & 1 & 2 & 3 & 3 & 2 \\
& $\mathrm{C}$ & 33 & 0 & 0 & 0 & 0 & 0 & 5 & 10 & 10 & 4 & 2 & 0 & 0 & 2 & 0 \\
\hline
\end{tabular}

$T P$ tongue piercing group, $C$ control group 
affecting the dentine are possible. In the study reported here, 115 teeth $(9.1 \%)$ in 19 subjects showed enamel fissures/cracks, mainly affecting the lingual surfaces. In group C, only 60 teeth $(4.8 \%)$ in 30 subjects were diagnosed with such damage which mainly affected the vestibular tooth surfaces. A similar situation was observed for enamel cracks. In group TP, 186 teeth (15\%) in 18 subjects were diagnosed with EC (group C: 56 teeth $=4.5 \%$ in 26 subjects). EC in group TP were mainly enamel/crown fractures (incisal enamel fractures) not affecting the dentine. A study of Levin et al. revealed a similar prevalence of tooth fractures in subjects wearing a TP (13.9\%). In this study, the central maxillary incisors were affected most [17]. In a further study, the prevalence of piercing-induced tooth damage was shown to be $41 \%$ [21]. Further, some authors have described a cumulative occurrence of plane abrasions on teeth- socalled chipping - in association with a TP $[1,4,9,12,14$ $16,24,27,32]$. Chipping seems to be an individual concomitant of TP, depending on the contact time on dental structures [15]. In the present study, "chipping" on anterior teeth were only diagnosed in some individual cases; they could not be attributed to the piercing object.

It should be noted that "playing" with the piercing object can cause diastema or misaligned teeth [4]. This was not determined by the present study. However, groove-shaped abrasions were observed for the first time (TP group 2.6\%). Some subjects wearing a TP demonstrated their habit and placed the piercing post at the lateral maxillary and mandibular teeth, exactly where the groove-shaped abrasion was found. Up until now, the available literature has not described this type of tooth enamel defect.

Lingual gingival recessions on the mandibular anterior teeth have also been described $[1,4,13,15,17,37,39-42]$. It appears that the longer and larger the piercing object and the farther anterior it is placed, the more marked the lingual recessions are [4]. Lingual recessions were determined on 97 teeth (7.7\%) in 27 subjects in group TP (group C: 8 subjects with 19 teeth $=1.5 \%$ ). Levin et al. found gingival recessions in 21 subjects $(26.6 \%)$, mainly at the mandibular incisors, thereby evaluating a comparable frequency [17]. Other studies have also demonstrated a cumulative occurrence of lingual recessions in subjects wearing a TP $[15,16,39]$.

According to Campbell et al., all complications described above are definitively influenced by the location and size of the piercing object, as well as its time in situ [15]. Lopez-Jornet and Camacho-Alonso have documented defects in teeth and periodontium after only 6 months in situ [42]. A relation between piercing localization and/or the time the piercing object had been in situ and the extent of damage could not be established in this study. Furthermore, the present study shows that most of the dental complications caused by TP, e.g. EF, EC and R, referred to the oral site of the upper and lower anterior teeth.
Limitation of the study: Food habits and use of soft drinks or fruit juices may have also influenced the results and worsened the effect of tongue piercing, but these questions were not asked and could therefore not be considered. Furthermore, oral hygiene and caries status may have influenced the results, especially since the oral hygiene and caries status in TP group was significantly worse than in the $\mathrm{C}$ group; a complementary statistical method was not carried out.

Implication for the practice: Dental professionals are seeing an increasing number of patients with oral piercings, but this is not the only reason why they should be able to inform their patients about the possible risks and complications associated with orofacial piercings. It is also important that the individual applying the piercing should provide comprehensive information about the possible risks of the procedure. However, this does not seem to be the case. Levin et al. reported that $58 \%$ of individuals in their study wearing a piercing object had not been informed in advance about the possible risks of an intraoral piercing [17]. In the present study, the majority of subjects (93.5\%) were informed about possible tooth damage before the piercing was carried out.

\section{Conclusion}

Within the limitations of this study, this case control study has demonstrated the adverse long-term effects of tongue piercing. A significant correlation between wearing a tongue piercing and an increased incidence of enamel fissures, enamel fractures and gingival recessions (especially in the lingual region of mandibular incisors) was revealed.

Based on this and other data available and the numerous dental complications which have been reported, individuals should be advised against having a tongue piercing. Subjects who already have a piercing object inserted should be informed with conviction about the risks they are facing.

Conflict of interests The authors declare that they have no conflict of interests.

Open Access This article is distributed under the terms of the Creative Commons Attribution Noncommercial License which permits any noncommercial use, distribution, and reproduction in any medium, provided the original author(s) and source are credited.

\section{References}

1. Boardman R, Smith RA (1997) Dental implications of oral piercing. Oral Health 87:23-31 
2. Folz BJ, Lippert BM, Kuelkens C, Werner JA (2000) Hazards of piercing and facial body art: a report of three patients and literature review. Ann Plast Surg 45:374-381

3. Farah CS, Harmon DM (1998) Tongue piercing: case report and review of current practice. Aust Dent J 43:387-389

4. Fehrenbach MJ (1998) Tongue piercing and potential oral complications. J Dent Hyg 72:23-25

5. Peticolas T, Tilliss TS, Cross-Poline GN (2000) Oral and perioral piercing: a unique form of self-expression. J Contemp Dent Pract $1: 30-46$

6. Scully C, Chen M (1994) Tongue piercing (oral body art). Br J Maxillofacial Surg 32:37-38

7. Price SS, Lewis MW (1997) Body piercing involving oral sites. J Am Dent Assoc 128:1017-1020

8. Reichl RB, Dailey JC (1996) Intraoral body piercing: a case report. Gen Dent 44:346-347

9. Levin L, Zadik Y (2007) Oral piercing: complications and side effects. Am J Dent 20:340-344

10. Ziebolz D, Stuehmer C, van Nüss K, Hornecker E, Mausberg RF (2009) Complications of tongue piercing: a review of the literature and three case reports. J Contemp Dent Pract 10:E065-71

11. DiAngelis AJ (1997) The lingual barbell: a new etiology for the cracked-tooth syndrome. J Am Dent Assoc 128:1438-1439

12. Maibaum WW, Margherita VA (1997) Tongue piercing: a concern for the dentist. Gen Dent 45:495-497

13. Kretschmer MC, Moriarty JD (2001) Metal piercing through the tongue and localized loss of attachment: a case report. J Periodontol 72:831-833

14. De Moor RJ, De Witte AM, De Bruyne MA (2000) Tongue piercing and associated oral and dental complications. Endod Dent Traumatol 16:232-237

15. Campbell A, Moore A, Williams E, Stephens J, Tatakis DN (2002) Tongue piercing: impact of time and barbell stem length on lingual gingival recession and tooth chipping. J Periodontol 73:289-297

16. Kieser JA, Thomson WM, Koopu P, Quick AN (2005) Oral piercing and oral trauma in a New Zealand sample. Dent Traumatol 21:254-257

17. Levin L, Zadik Y, Becker T (2005) Oral and dental complications of intra-oral piercing. Dent Traumatol 21:341-343

18. De Moor RJ, De Witte AM, Delme KI, De Bruyne MA, Hommez GM, Goyvaerts D (2005) Dental and oral complications of lip and tongue piercing. Br Dent J 199:506-509

19. Stead LR, Williams JV, Williams AC, Robinson CM (2006) An investigation into the practice of tongue piercing in the South West of England. Br Dent J 200:103-107

20. Bone A, Ncube F, Nichols T, Noah ND (2008) Body piercing in England: a survey of piercing at sites other than earlobe. BMJ 21 336(7658):1426-1428

21. Pearose MM, Perinpanayagam MK, ChinKit-Wells MD (2006) Trends in oral piercing in Buffalo, New York high schools. NY State Dent J 72:30-32
22. Venta I, Lakoma A, Haahtela S, Peltola J, Ylipaavalniemi P, Turtola L (2005) Oral piercings among first-year university students. Oral Surg Oral Med Oral Pathol 99:546-549

23. Bui E, Rodgers R, Cailhol L, Birmes P, Chabrol H, Schmitt L (2010) Body piercing and psychopathology: a review of the literature. Psychother Psychosom 79:125-129

24. Botchway C, Kuc I (1998) Tongue piercing and associated tooth fracture. J Can Dent Assoc 64:803-805

25. Bassiouny MA, Deem LP, Deem TE (2001) Tongue piercing: a restorative perspective. Quintessence Int 32:477-481

26. Chen M, Scully C (1992) Tongue piercing: a new fad in body art. Br Dent J 172:87

27. Croll TP (1999) "Wrecking ball" dental fractures: report of 2 cases. Quintessence Int 30:275-277

28. Jeger F, Lussi A, Zimmerli B (2009) Summary about oral jewelry. Schweiz Monatsschr Zahnmed 119:615-623 [in German]

29. Hardee PS, Mallya LR, Hutchison IL (2000) Tongue piercing resulting in hypotensive collapse. Br Dent J 188:657-658

30. Keogh IJ, O'Leary G (2001) Serious complication of tongue piercing. J Laryngol Otol 115:233-234

31. Perkins CS, Meisner J, Harrison JM (1997) A complication of tongue piercing. Br Dent J 182:147-148

32. Ram D, Peretz B (2000) Tongue piercing and insertion of metal studs: three cases of dental and oral consequences. J Dent Child 5:326-329

33. Theodossy T (2003) A complication of tongue piercing. a case report and review of the literature. Br Dent J 194:551-552

34. Shinohara EH, Horikawa FK, Martinson Ruiz M, Shinohara MT (2007) Tongue piercing: case report of a local complication. J Contemp Dent Pract 8:83-89

35. Lopez-Jornet P, Camacho-Alonso F, Pons-Fuster JM (2005) A complication of lingual piercing: a case report. Oral Surg Oral Med Oral Pathol Oral Radiol Endod 99:E18-19

36. Maheu-Robert L-F, Andrian E, Grenier D (2007) Overview of complications secondary to tongue and lip piercing. J Can Dent Assoc 73:327-331

37. Brennan M, O'Connell O'Sullivan (2006) Multiple dental fractures following tongue barbell placement: a case report. Dent Traumatol 22:41-43

38. Cobb DS, Denehy GE, Vargas MA (1998) Adhesive composite inlays for the restoration of cracked posterior teeth associated with a tongue bar. Pract Periodontics Aesthet Dent 10:453-460

39. Brooks JK, Hooper KA, Reynolds MA (2003) Formation of mucogingival defects associated with intraoral and perioral piercing: case reports. J Am Dent Assoc 134:837-843

40. Er N, Ozkavaf A, Berberoglu A, Yamalik N (2000) An unusual cause of gingival recession: oral piercing. J Periodontol 71:1767-1769

41. Kapferer I, Benesch T, Gregoric N, Ulm C, Hienz SA (2007) Lip piercing: prevalence of associated gingival recession and contributing factors. a cross-sectional study. J Periodontal Res 42:177-183

42. Lopez-Jornet P, Camacho-Alonso F (2006) Oral and dental complications of intra-oral piercing. J Adolesc Health 38:767-769 